\title{
Inhalation of 7.5\% Carbon Dioxide Increases Threat Processing in Humans
}

\author{
Matthew Garner ${ }^{1,2}$, Angela Attwood ${ }^{3}$, David S Baldwin', Alexandra James ${ }^{3}$ and Marcus R Munafó ${ }^{3}$ \\ 'Clinical Neuroscience Division, School of Medicine, University of Southampton, Southampton, UK; ${ }^{2}$ School of Psychology, University of \\ Southampton, Southampton, UK; ${ }^{3}$ School of Experimental Psychology, University of Bristol, Bristol, UK
}

\begin{abstract}
Inhalation of 7.5\% $\mathrm{CO}_{2}$ increases anxiety and autonomic arousal in humans, and elicits fear behavior in animals. However, it is not known whether $\mathrm{CO}_{2}$ challenge in humans induces dysfunction in neurocognitive processes that characterize generalized anxiety, notably selective attention to environmental threat. Healthy volunteers completed an emotional antisaccade task in which they looked toward or away from (inhibited) negative and neutral stimuli during inhalation of $7.5 \% \mathrm{CO}_{2}$ and air. $\mathrm{CO}_{2}$ inhalation increased anxiety, autonomic arousal, and erroneous eye movements toward threat on antisaccade trials. Autonomic response to $\mathrm{CO}_{2}$ correlated with hypervigilance to threat (speed to initiate prosaccades) and reduced threat inhibition (increased orienting toward and slower orienting away from threat on antisaccade trials) independent of change in mood. Findings extend evidence that $\mathrm{CO}_{2}$ triggers fear behavior in animals via direct innervation of a distributed fear network that mobilizes the detection of and allocation of processing resources toward environmental threat in humans.

Neuropsychopharmacology (20II) 36, I557-I562; doi: I0.1038/npp.20I I.I5; published online I3 April 20I I
\end{abstract}

Keywords: $\mathrm{CO}_{2}$; anxiety; cognition; attention; emotion processing; antisaccade

\section{INTRODUCTION}

The development of experimental models of anxiety that readily translate between animals and humans is required to better integrate and clarify the biological, behavioral, and cognitive mechanisms that underlie anxiety disorders and mediate response to treatment.

Inhalation of $7.5 \% \mathrm{CO}_{2}$ for $20 \mathrm{~min}$ increases self-report anxiety (eg, worry, tension) and autonomic arousal (eg, heart rate, blood pressure), and provides a novel experimental model of generalized anxiety disorder (GAD) in healthy humans (Bailey et al, 2005) that quantitatively and qualitatively differs from the established single vital capacity inhalation of $35 \% \mathrm{CO}_{2}$ model of panic (van den Hout and Griez, 1984; see Colasanti et al, 2008 for detailed characterization of panic symptoms following $35 \%$ challenge in healthy volunteers). Evidence that acute benzodiazepine administration and chronic administration of selective serotonin reuptake inhibitors both attenuate subjective response to $7.5 \%$ challenge in healthy volunteers is consistent with their efficacy in patients with GAD,

Correspondence: Dr M Garner, Clinical Neuroscience Division, School of Psychology, University of Southampton, Highfield, Hampshire, Southampton SO 17 IBJ, UK, Tel: + 44 (0) 2380595926 ,

Fax: + 44 (0) 238059 4597, E-mail: m.j.garner@soton.ac.uk

Received 9 November 2010; revised I5 December 2010; accepted 17

December 2010 and further validates the $7.5 \% \mathrm{CO}_{2}$ model in humans (Bailey et al, 2007).

In rodents, inhalation of $10 \% \mathrm{CO}_{2}$ triggers significant freezing behavior, reduced activity in an open-field test, and greater contextual fear conditioning, consistent with the anxiety phenotype (Ziemann et al, 2009). Recent evidence confirms the amygdala as an important chemosensor that directly detects increases in $\mathrm{CO}_{2}$ (via the acid-sensing ionchannel ASICla, which is sensitive to localized reductions in $\mathrm{pH}$ ) to elicit fear behavior in mice (Ziemann et al, 2009).

Human neurocognitive models of anxiety propose a common amygdala-prefrontal circuitry that underlies fear behaviour and dysfunctional cognitive processes that promote the detection and selection of threat, and increase distractibility to task-irrelevant information in anxiety (Bishop, 2007; Davis and Whalen, 2001; Davidson, 2002). Amygdala hyperactivity to threat has been observed in healthy individuals with high levels of state anxiety (Bishop et al, 2004a), high levels of generalized trait anxiety (Stein et al, 2007), and in patients with GAD (Nitschke et al, 2009), and is strongly correlated with attention to threat in GAD (Monk et al, 2008).

Dysfunction in prefrontal cortex is observed when anxious individuals process threat distracters (Bishop et al, 2004b) and lateral prefrontal cortex is implicated in mediating the modification of attentional bias to threat stimuli in healthy volunteers (Browning et al, 2010). Furthermore, high levels of generalized trait anxiety are 
associated with reduced structural integrity in amygdalaprefrontal pathways (assessed using diffusion tensor imaging; Kim and Whalen, 2009) and reduced (negative) functional connectivity between prefrontal cortex and amygdala during threat processing (Monk et al, 2008; for discussion of dysfunction in additional structures, eg, insula, see Paulus and Stein, 2006; Stein et al, 2007).

Together these findings are consistent with cognitive models of anxiety which emphasize increased activation of threat-related representations and a failure to use controlled processing to regulate attention and emotion in the etiology of anxiety (Eysenck et al, 2007), and with extensive behavioral evidence of increased attention to environmental threat in anxiety (review by Bar-Haim et al, 2007).

In the antisaccade task, top-down attention control is required to suppress (inhibit) reflexive saccades (eye movements) toward abrupt peripheral visual stimuli and instead generate a volitional saccade in the opposite direction ('antisaccade'). Enhanced activity in prefrontal cortex (dorsolateral and ventrolateral) during (correct) antisaccade trials supports the involvement of these regions in regulating attention allocation by inhibiting reflexive attentional capture by distracters (Ettinger et al, 2008). Previous research with the antisaccade task has revealed deficits in attention control in individuals with high generalized trait anxiety (Garner et al, 2009; Ansari et al, 2008).

Although inhalation of low concentrations of $\mathrm{CO}_{2}$ increase anxiety and autonomic arousal in humans and triggers fear behavior coordinated by the amygdala in small rodents, its effects on human neurocognitive mechanisms considered to underlie anxiety (eg, selective attention to threat) are not known. The present study therefore examined whether $7.5 \% \mathrm{CO}_{2}$ challenge (relative to normal air) increases attention toward and impairs inhibition of threat stimuli within a modified emotional variant of the antisaccade task.

\section{PARTICIPANTS AND METHODS}

\section{Participants}

A total of 26 healthy volunteers (12 women; mean age 21.3 years, $\mathrm{SD}=3.0$ years) were recruited from the local community. Participants attended a pretest screening interview during which they underwent a short structured diagnostic interview based on DSM-IV criteria (Mini International Neuropsychiatric Interview; Sheehan et al, 1998). Exclusion criteria included recent use of medication (past 8 weeks bar local treatment, occasional aspirin or paracetamol, oral, injectable, or skin patch contraception), pregnancy, history of asthma/respiratory illness, high blood pressure ( $>140 / 90 \mathrm{~mm} \mathrm{Hg}$ ), cardiovascular disease, migraines, current or lifetime history of psychiatric illness (including lifetime history/family history of panic attacks), smoker, under- or overweight (body mass index $<18$ or $\geqslant 28 \mathrm{~kg} / \mathrm{m}^{2}$ ), current or past drug or alcohol dependence, and recent use of illicit drugs (urine screen) or alcohol (breath test). Participant levels of generalized trait anxiety (Spielberger et al, 1983: $m=34.8, \mathrm{SD}=7.2$ ) and fear of anxiety sensations (anxiety sensitivity, Taylor and Cox, $1998 ; m=14.3, \mathrm{SD}=6.2$ ) are indicative of those reported in healthy control samples.

\section{Procedure}

Participants attended a single test session in which they completed an emotional variant of the antisaccade task during $20 \mathrm{~min}$ inhalation of $7.5 \% \mathrm{CO}_{2}$ and air. Gas was administrated blind to participants through an oronasal face mask with order of gas presentation counterbalanced across participants. Heart rate, diastolic and systolic blood pressure (Omron-M6, Medisave, UK), subjective ratings of current anxiety (state version of the STAI; Spielberger et al, 1983), and positive and negative affect (PANAS; Watson et al, 1988) were measured at pretest baseline and immediately following inhalation of air and $7.5 \% \mathrm{CO}_{2}$.

\section{Antisaccade Task}

Eight negative and eight neutral color images were selected from the International Affective Picture Set (Center for the Study of Emotion and Motivation, Gainesville, FL, 1999) on the basis of normative valence ratings (scale -4 to +4 ) and arousal ratings $(0-8$; negative images: mean valence $=-3.1$ and mean arousal $=5.8$; neutral images: mean valence $=1.2$ and mean arousal $=2.9$ ). Images subtended $8 \times 5.5$ visualdeg (at $57 \mathrm{~cm})$. On each trial, an instruction word (either 'TOWARDS' or 'AWAY') was presented at central fixation for $2000 \mathrm{~ms}$. At $200 \mathrm{~ms}$ following word offset, the picture stimulus was presented for $600 \mathrm{~ms}\left(6^{\circ}\right.$ to the left or right of central fixation). On prosaccade ('TOWARDS') trials, participants were required to look toward the picture and on antisaccade ('AWAY') trials to look away from it (ie, to shift their gaze to the opposite side of the screen). Images were presented 6 times (balanced across conditions) throughout 96 fully randomized experimental trials. Participants completed eight practice trials in which they completed pro- and antisaccades to a peripheral yellow rectangle. To increase task demand on each trial, participants classified the direction of a small arrow $(\uparrow$ or $\downarrow$ ) presented at $50 \mathrm{~ms}$ following picture offset (arrow-picture location congruent on $50 \%$ of trials per trial type). The mean intertrial interval was $1000 \mathrm{~ms}$ (range $750-1250 \mathrm{~ms}$ ). Stimuli were presented using Inquisit 2 Computer software, Millisecond Software, Seattle, WA. Horizontal eye movements were measured by electrooculography and sampled at $1000 \mathrm{~Hz}$ (MP150-amplifier and AcqKnowledge-3.8.1 software, Biopac-Systems, Goleta, CA).

During each inhalation period, participants also completed a short $(5 \mathrm{~min})$ face classification task. This task addressed different research questions to those of the present study and results are to be reported elsewhere by different authors. Task order was counterbalanced across participants and did not interact with or moderate the observed effects of $\mathrm{CO}_{2}$ on eye movements to threat, reported below (ie, gas $\times$ trial type $\times$ image valence $\times$ task order, $\mathrm{F}<1, p=0.98)$.

\section{Data Analysis}

Saccade direction and latency were scored manually and blind to trial type and inhalation condition using AcqKnowledge software. Saccades with a latency less than $100 \mathrm{~ms}$ (ie, reflecting anticipatory eye movements $=2.1 \%$ of data) or that subtended less than 6 horizontal degrees (ie, did not terminate in the location/mirror location 
Table I Anxiety, Mood, Blood Pressure, and Heart Rate at Baseline and Following 7.5\% $\mathrm{CO}_{2}$ and Normal Air Inhalation

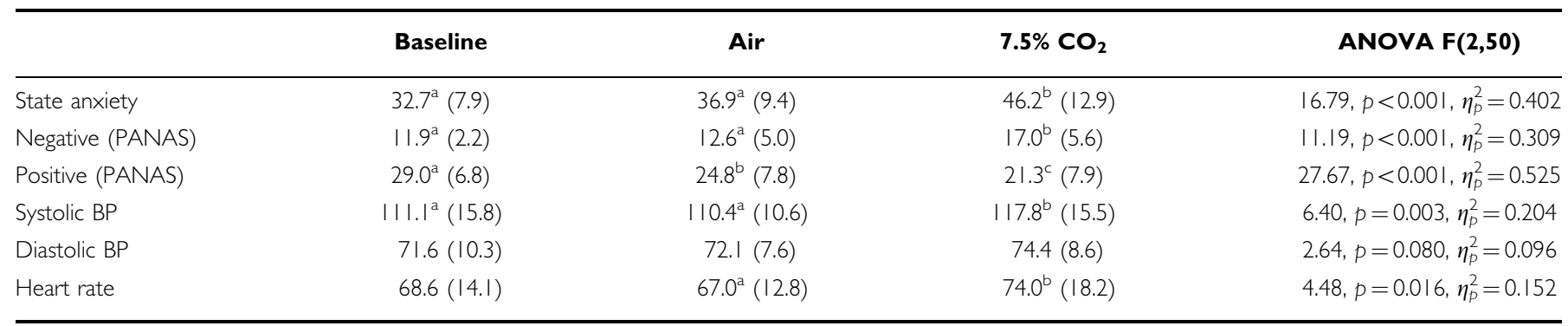

Within each measure (row), mean values with different superscripts ( $a, b, c)$ significantly differ from each other, $p$ 's $<0.05$.

of the picture $=0.8 \%$ of data) were removed from analyses. The amount of missing data did not vary across conditions. Saccade accuracy and latencies for correct saccades were entered into separate repeated-measures analysis of variance (ANOVA) with inhalation (7.5\% $\mathrm{CO}_{2}$ vs air), trial type (pro $v s$ antisaccade), and image valence (negative $v s$ neutral) as independent variables.

\section{RESULTS}

Inhalation of $7.5 \% \mathrm{CO}_{2}$ produced significant increases in anxiety, negative affect, blood pressure, and heart rate, and a significant decrease in positive affect compared with inhalation of air and pretest baseline, see Table 1 .

\section{Saccade Accuracy}

A significant gas $\times$ trial type $\times$ image valence interaction $\left(\mathrm{F}(1,25)=6.761, p=0.015\right.$, and $\left.\eta_{p}^{2}=0.213\right)$ was characterized by a significant gas $\times$ valence interaction for antisaccade $\left(\mathrm{F}(1,25)=6.882, p=0.015\right.$, and $\left.\eta_{p}^{2}=0.216\right)$, but not prosaccade trials ( $\mathrm{F}$ values $<1$ ). $\mathrm{CO}_{2}$ inhalation significantly increased antisaccade errors, ie, erroneous eye movements toward negative stimuli compared with (i) neutral stimuli presented during $\mathrm{CO}_{2}$ inhalation; $t(25)=2.17, p=0.04$, and $d=0.213$; and (ii) both negative and neutral stimuli presented during air inhalation; $t(25)$ values $>2.35$, $p$-values $<0.027$, and $d$ values $>0.20$, see Figure 1 (panel a).

\section{Saccade Latency}

ANOVA revealed a significant gas $\times$ trial type interaction $\left(\mathrm{F}(1,25)=4.482, p=0.044\right.$, and $\left.\eta_{p}^{2}=0.152\right) . \mathrm{CO}_{2}$ inhalation significantly delayed the time taken to correctly initiate antisaccades $\left(\mathrm{CO}_{2}: m=305 \mathrm{~ms}\right.$ and $\mathrm{SD}=72$; air: $m=$ $289 \mathrm{~ms}, \mathrm{SD}=50 ; t(25)=2.04$; and $p=0.04)$, but did not affect prosaccade latencies $\left(\mathrm{CO}_{2}: m=201 \mathrm{~ms}\right.$ and $\mathrm{SD}=54$; air: $m=203 \mathrm{~ms}$ and $\mathrm{SD}=44 ; \mathrm{t}<1)$. All other results were non-significant. Analysis of latencies for incorrect saccades did not reveal significant results.

\section{Associations between Self-Report and Autonomic Response to $\mathrm{CO}_{2}$ Challenge and Antisaccade Performance}

Change scores were calculated to reflect the degree of $\mathrm{CO}_{2}$-induced increases in (i) subjective (self-report state anxiety) and autonomic response, (ii) proportion of erroneous eye movements toward negative $v s$ neutral stimuli on antisaccade trials, (iii) time taken to correctly orient away from (ie, inhibit) negative $v s$ neutral stimuli on antisaccade trials, and (iv) speed to correctly orient toward negative $v s$ neutral stimuli on prosaccade trials.

$\mathrm{CO}_{2}$-induced increase in blood pressure was significantly associated with (i) erroneous eye movements toward negative relative to neutral stimuli on antisaccade trials ( $r=0.47, p=0.01$ ), (ii) time taken to correctly orient away from negative relative to neutral stimuli on antisaccade trials (see Figure 1b), and (iii) speed to correctly initiate eye movements toward negative relative to neutral images on prosaccade trials (Figure $1 \mathrm{c}$ ). Change in blood pressure was not associated with subjective response to $\mathrm{CO}_{2}$ challenge. Associations between autonomic response and both attention toward and impaired inhibition of threat remained significant after controlling for change in subjective anxiety $(p$-values $\leqslant 0.01)$.

Increased heart rate following $\mathrm{CO}_{2}$ inhalation (relative to baseline) was associated with increased state anxiety (relative to baseline, $r=0.44$ and $p<0.05$ ) but neither measure was correlated with performance measures on the antisaccade task. Individual differences in trait anxiety and anxiety sensitivity were not associated with subjective or physiological response to $\mathrm{CO}_{2}$, nor antisaccade performance.

\section{$\mathrm{CO}_{2}$ Challenge in Males and Females}

Mixed-design ANOVA with participant gender as a betweensubject factor confirmed that subjective, autonomic, and behavioral responses to $\mathrm{CO}_{2}$ challenge were unaffected by the gender of the participant (effects of gender on subjective measures: $F$ values $(2,48)<1.95$ and $p$-values $>0.15$; autonomic measures: $F$ values $(2,48)<1.99$ and $p$-values $>0.15$; and eye-movement measures: $F$ values $<1$ ).

\section{Reliability Analysis}

Split half correlations confirmed high levels of reliability for saccade accuracy scores (per gas $\times$ trial type $\times$ valence condition: $r$ values $>0.68$ and $p$-values $<0.001)$ and saccade latency scores (per gas $\times$ trial type $\times$ valence condition: $r$ values $>0.61$ and $p$-values $\leqslant 0.001)$, and recommend our task for future within-subject (pharmacological) challenge studies that wish to index attentional bias to threat. Furthermore the effects of $7.5 \% \mathrm{CO}_{2}$ inhalation on 

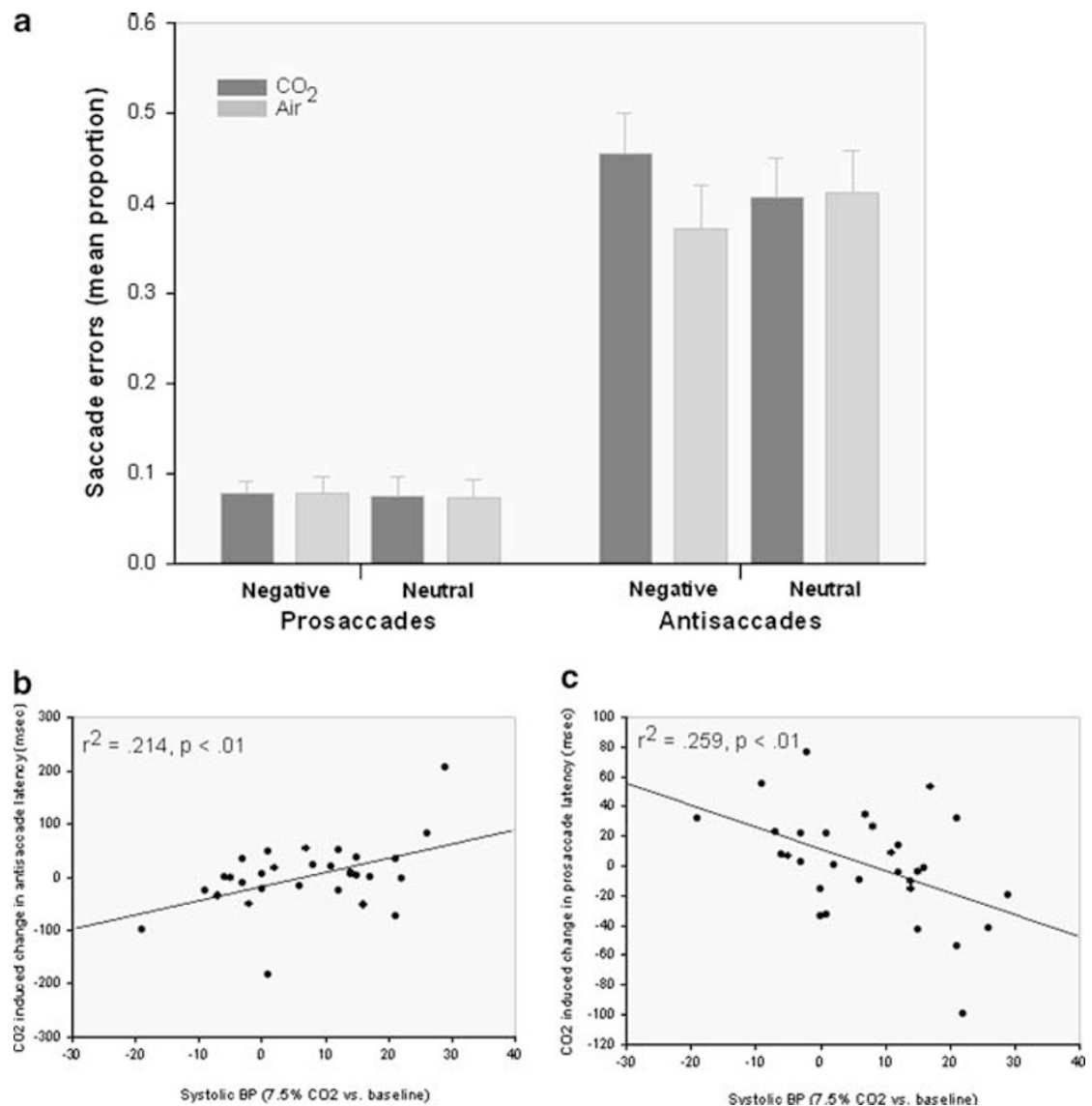

Figure I Prosaccade and antisaccade errors in response to negative and neutral stimuli presented during inhalation of $7.5 \% \mathrm{CO}_{2}$ and air (a). Relationships between systolic blood pressure response to $\mathrm{CO}_{2}$ challenge and latency to initiate correct antisaccades away from (b) and correct prosaccades toward (c) negative (vs neutral stimuli) within $\mathrm{CO}_{2}$ relative to air.

erroneous eye movements to threat did not differ between the first and second half of the antisaccade task (gas $\times$ trial type $\times$ image valence $\times$ task half: $F(1,25)=1.21$ and $p=0.28$ ), further demonstrating the stability over time of interactions between $\mathrm{CO}_{2}$ and attention to threat.

\section{DISCUSSION}

Our findings are the first to show that $7.5 \% \mathrm{CO}_{2}$ inhalation can trigger dysfunction in neurocognitive mechanisms that characterize generalized anxiety. Inhalation of $7.5 \% \mathrm{CO}_{2}$ induced erroneous eye movements toward negative stimuli on antisaccade trials, consistent with evidence that patients with GAD more readily orient toward threat stimuli in other eye-tracking paradigms (Mogg et al, 2000).

$\mathrm{CO}_{2}$ challenge substantially increased self-report anxiety and autonomic arousal, consistent with previous findings (Bailey et al, 2005), and revealed correlations between subjective (state anxiety) response to $\mathrm{CO}_{2}$ and increases in heart rate, but not blood pressure (likely reflecting the greater interoceptive salience/awareness of heart rate when determining subjective levels of distress).

Blood pressure response to challenge was strongly associated with $\mathrm{CO}_{2}$-induced deficits in threat inhibition (ie, greater orienting toward and slower orienting away from threat on antisaccade trials), and was further associated with faster eye movements toward threat on prosaccade trials. These associations reflect a large effect size and $\mathrm{CO}_{2}-$ induced increases in blood pressure and selective attention to threat were of comparable magnitude (small-medium effect sizes). However their covariation could be further clarified by measuring autonomic response throughout the inhalation period (in addition to immediately afterward as in our study).

The strong relationships between induced change in blood pressure and attention to threat remained significant after controlling for $\mathrm{CO}_{2}$ induced change in state anxiety (which itself was not correlated with induced attention to threat). Furthermore additional analysis of those participants who did not report an increase in state anxiety in response to $\mathrm{CO}_{2}(n=5)$ replicated findings from the entire group: notably a significant interaction between gas inhalation and valence on antisaccade errors characterized by greater erroneous eye-movements towards threat relative to neutral images during $\mathrm{CO}_{2}$ relative to air $[\mathrm{F}(1,4)=12.78$, $p=0.023$ ]. These findings demonstrate that inhalation of $7.5 \% \mathrm{CO}_{2}$ can induce hyper-vigilance towards and deficient inhibition of threat in humans independent of changes in subjective mood. Future studies should clarify the extent to which $7.5 \% \mathrm{CO}_{2}$ modulates attention to threat independent of changes in subjective mood through direct comparison of $\mathrm{CO}_{2}$ challenge with non-pharmacological mood induction procedures that can further control for subjective anxiety 
(such as Hayes et al, 2008; anticipatory worry period of the Trier social stress test, Kirschbaum et al, 1993). Future evidence that $7.5 \% \mathrm{CO}_{2}$ and non-pharmacological stressors known to trigger characteristics associated with GAD (eg, worry, nervous apprehension) produce comparable subjective response profiles that differ from the effects of $35 \%$ $\mathrm{CO}_{2}$ challenge, would lend further support to proposals that the $7.5 \% \mathrm{CO}_{2}$ challenge models $\mathrm{GAD}$, rather than acute fear and panic.

Supplementary analyses confirmed that $\mathrm{CO}_{2}$-induced change in antisaccade performance was not affected by the duration of inhalation either before commencing or during the antisaccade task. This is consistent with evidence that the autonomic effects of $7.5 \% \mathrm{CO}_{2}$ rise early in the inhalation period and then plateau with minor fluctuations (Poma et al, 2005; Bailey et al, 2005). Studies have yet to examine variation in subjective effects during inhalation, and it would be of interest to directly assess the temporal characteristics and covariation of subjective, autonomic (including respiration rate/volume), and neurocognitive processing of threat (and positive/neutral control stimuli) throughout the $\mathrm{CO}_{2}$ inhalation period.

Our findings complement evidence that $10 \% \mathrm{CO}_{2}$ elicits anxious behavior in rodents (Ziemann et al, 2009). Recent evidence that $\mathrm{CO}_{2}$ triggers fear behavior in rats via ASCla in amygdala suggests a mechanism through which $\mathrm{CO}_{2}$ can increase the salience of environmental threat cues, interrupt goal-directed behavior, direct processing resources to threat through interactions with prefrontal cortex (Bishop et al, 2004b; Davidson, 2002), and comodulate autonomic response. Future research should clarify the extent to which $\mathrm{CO}_{2}$-induced threat processing in humans reflects amygdalic innervation of norepinephrine via the locus coeruleus (also subjected to direct regulation by $\mathrm{CO}_{2}$ (Pineda and Aghajanian, 1997) and implicated in both response to $\mathrm{CO}_{2}$ challenge (Bailey et al, 2003) and attention (Grefkes et al, 2010)) and interactions with GABAergic mechanisms involved in response to $\mathrm{CO}_{2}$ challenge and threat inhibition (Bailey and Nutt, 2008).

Our findings show clear effects of $7.5 \% \mathrm{CO}_{2}$ inhalation on selective attention to threat in healthy humans and further validate the $\mathrm{CO}_{2}$ model as a promising unconditioned cross-species translational tool with which to challenge (and evaluate novel treatments that aim to resolve) subjective, autonomic, and neurocognitive processes that underlie anxious behavior in humans, and which characterize the generalized anxiety phenotype.

\section{ACKNOWLEDGEMENTS}

This research was supported, in part, by a National Alliance for Research on Schizophrenia and Depression Young Investigator Award to MRM. We are grateful to Charlotte Sykes for help with data collection.

\section{DISCLOSURE}

DB has acted as a paid consultant to a number of companies with an interest in anxiety and depressive disorders (Eli Lilly, GlaxoSmithKline, Lundbeck, Pfizer, and Servier) and holds or has held research grants (on behalf of his employer) from Lundbeck and Pfizer. He has accepted paid speaking engagements in industry-supported satellite symposia at international and national meetings organized by Lundbeck, Pfizer, and Servier. The remaining authors declare no conflict of interest.

\section{REFERENCES}

Ansari TL, Derakshan N, Richards A (2008). Effects of anxiety on task switching: evidence from the mixed antisaccade task. Cogn Affect Behav Neurosci 8: 229-238.

Bailey JE, Argyropoulos SV, Kendrick AH, Nutt DJ (2005). Behavioral and cardiovascular effects of $7.5 \% \mathrm{CO}_{2}$ in human volunteers. Depress Anxiety 21: 18-25.

Bailey JE, Argyropoulos SV, Lightman SL, Nutt DJ (2003). Does the brain noradrenaline network mediate the effects of the $\mathrm{CO}_{2}$ challenge? J Psychopharmacol 17: 252-259.

Bailey JE, Kendrick A, Diaper A, Potokar JP, Nutt DJ (2007). A validation of the $7.5 \% \mathrm{CO}_{2}$ model of GAD using paroxetine and lorazepam in healthy volunteers. J Psychopharmacol 21: 42-49.

Bailey JE, Nutt DJ (2008). GABA-A receptors and the response to $\mathrm{CO}_{2}$ inhalation - a translational trans-species model of anxiety? Pharmacol Biochem Be 90: 51-57.

Bar-Haim YD, Lamy D, Pergamin L, Bakermans-Kranenburg MJ, vanljendoorn $\mathrm{MH}$ (2007). Threat-related attentional bias in anxious and nonanxious individuals: a meta-analytic study. Psychol Bull 133: 1-24.

Bishop SJ (2007). Neurocognitive mechanisms of anxiety: an integrative account. Trends Cogn Sci 11: 307-316.

Bishop SJ, Duncan J, Lawrence AD (2004a). State anxiety modulation of the amygdala response to unattended threatrelated stimuli. J Neurosci 24: 10364-10368.

Bishop S, Duncan J, Lawrence AD (2004b). Prefrontal cortical function and anxiety: controlling attention to threat-related stimuli. Nat Neurosci 7: 184-188.

Browning M, Holmes EA, Murphy SE, Goodwin GM (2010). Lateral Prefrontal Cortex Mediates the Cognitive Modification of Attentional Bias. Biological Psychiatry 67: 919-925.

Center for the Study of Emotion and Attention (1999). The International Affective Picture System (IAPS). Gainesville, FL: The Center for Research in Psychophysiology, University of Florida.

Colasanti A, Salamon E, Schruers K, van Diest R, van Duinen M, Griez EJ (2008). Carbon dioxide-induced emotion and respiratory symptoms in healthy volunteers. Neuropsychopharmacol 33: 3103-3110.

Davidson RJ (2002). Anxiety and affective style: role of prefrontal cortex and amygdala. Biol Psychiatry 51: 68-80.

Davis M, Whalen PJ (2001). The amygdala: vigilance and emotion. Mol Psychiatry 6: 13-34.

Ettinger U, Ffytche DH, Kumari V, Kathmann N, Reuter B, Zelaya F et al (2008). Decomposing the neural correlates of antisaccade eye movements using event-related fMRI. Cereb Cortex 18: 1148-1159.

Eysenck MW, Derakshan N, Santos R, Calvo MG (2007). Anxiety and cognitive performance: attentional control theory. Emotion 7: 336-353.

Garner M, Ainsworth B, Gould H, Gardner H, Baldwin DS (2009). Impaired attentional control in high and low anxious healthy volunteers: evidence from the antisaccade task. Eur Neuropsychopharm 19: S599.

Grefkes C, Wang LE, Eickhoff SB, Fink GR (2010). Noradrenergic modulation of cortical networks engaged in visuomotor processing. Cereb Cortex 20: 783-797.

Hayes S, Hirsch C, Mathews A (2008). Restriction of working memory capacity during worry. J Abnorm Psychol 117: 712-717.

Kim MJ, Whalen PJ (2009). The structural integrity of an amygdala-prefrontal pathway predicts trait anxiety. I Neurosci 29: $11614-11618$. 
Kirschbaum C, Pirke KM, Hellhammer DH (1993). The Trier Social Stress Test-a tool for investigating psychobiological stress responses in a laboratory setting. Neuropsychobiology 28: 76-81.

Mogg K, Millar N, Bradley BP (2000). Biases in eye movements to threatening facial expressions in generalized anxiety disorder and depressive disorder. J Abnorm Psychol 109: 695-704.

Monk CS, Telzer EH, Mogg K, Bradley BP, Mai XQ, Louro HMC et al (2008). Amygdala and ventrolateral prefrontal cortex activation to masked angry faces in children and adolescents with generalized anxiety disorder. Arch Gen Psychiat 65: 568-576.

Nitschke JB, Sarinopoulos I, Oathes DJ, Johnstone T, Whalen PJ, Davidson RJ et al (2009). Anticipatory activation in the amygdala and anterior cingulate in generalized anxiety disorder and prediction of treatment response. Am J Psychiatry 166: 302-310.

Paulus MP, Stein MB (2006). An insular view of anxiety. Biol Psychiatry 60: 383-387.

Pineda J, Aghajanian GK (1997). Carbon dioxide regulates the tonic activity of locus coeruleus neurons by modulating a proton- and polyamine-sensitive inward rectifier potassium current. Neuroscience 77: 723-743.

Poma SZ, Milleri S, Squassante L, Nucci G, Bani M, Perini GI et al (2005). Characterization of a $7 \%$ carbon dioxide (CO2) inhalation paradigm to evoke anxiety symptoms in healthy subjects. J Psychopharmacol 19: 494-503.
Sheehan DV, Lecrubier Y, Harnett-Sheehan K, Amorim P, Janavs J, Weiller E et al (1998). The Mini International Neuropsychiatric Interview (M.I.N.I.): the development and validation of a structured diagnostic psychiatric interview. J Clin Psychiatry 59: 22-33.

Spielberger CD, Gorsuch RL, Lushene R, Vagg PR, Jacobs GA (1983). Manual for the State-Trait Anxiety Inventory. Palo Alto, CA: Consulting Psychologists Press.

Stein MB, Simmons AN, Feinstein JS, Paulus MP (2007). Increased amygdala and insula activation during emotion processing in anxiety-prone subjects. Am J Psychiatry 164: 318-327.

Taylor S, Cox BJ (1998). An expanded anxiety sensitivity index: evidence for a hierarchic structure in a clinical sample. J Anxiety Disord 12: 463-483.

Van Den Hout MA, Griez E (1984). Panic symptoms after inhalation of carbon dioxide. Brit J Psychiat 144: 503-507.

Watson D, Clark LA, Tellegen A (1988). Development and validation of brief measures of positive and negative affect: the PANAS scale. J Pers Soc Psychol 54: 1063-1070.

Ziemann AE, Allen JE, Dahdaleh NS, Drebot II, Coryell MW, Wunsch AM et al (2009). The amygdala is a chemosensor that detects carbon dioxide and acidosis to elicit fear behavior. Cell 139: 1012-1021. 